\title{
Potential Health Benefits in Controlling Type 2 Diabetes of Resistant Starches in Taro (Colocasia Esculenta) Flour Stored During 5 Months
}

\author{
Aboubakar* \\ Department of renewable energies, Cameroon \\ *Corresponding author: Aboubakar, Department of renewable energies, Cameroon

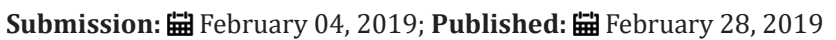

\begin{abstract}
Non-insulin-dependent or type 2 diabetes mellitus is on the rise in the urban population. The exact cause is unknown. Malnutrition, defective intake of essential fatty acids and reduced intake of fibres are found in urban diet, and dietary factors may be one of the causes leading to increased incidence of the disease. Dietary fibers reduce blood glucose and cholesterol levels. Resistant starches behave as dietary fiber. This study evaluated the potential health benefits in controlling type 2 diabetes of resistant starches in taro (colocasia esculenta) flour stored for 5 months. For this purpose, flour was produced from boiled taro tubers. Cooked tubers were sun dried using a solar dryer, ground through a $500 \mu \mathrm{m}$ sieve and further sieved using 250,150 and $75 \mu \mathrm{m}$ sieves. Flours were sealed in polyethylene bags and kept at ambient temperature $\left(25^{\circ} \mathrm{C}\right)$ and at $4{ }^{\circ} \mathrm{C}$. One set of flour not sealed was exposed at $25^{\circ} \mathrm{C}$. Flours were stored for 5 months. Resistant starch was quantified directly in the residue obtained after removing digested starch in simulated physiological conditions. Changes in blue index value and soluble sugars of cooked taro were also analysed. The results showed that irrespective of the particle size, the resistant starch significantly increased while BVI and soluble sugar significantly decreased. Significant correlations $(R=0.59, p<0.05 ; R=0.68, p<0.05)$, were observed between the resistant starch and the BVI and soluble sugar respectively. In fact, the degree of variations of each parameter depends mainly on the storage level.
\end{abstract}

Keywords: Taro flour; Resistant starch; Storage; Particle size; Diabetes

\section{Introduction}

Resistant starch show, potential health benefits which may result in much disease prevention and reduction of sufferings [1]. Among these diseases, type 2 diabetes is one of the most dangerous [2]. This disease is known as a metabolic disorder that is primarily characterized by insulin resistance, relative insulin deficiency and hyperglycemia [3]. Thus, diabetics are recommended to eat a balanced diet containing normal amounts of carbohydrates preferably those with low glycemic index [4]. Taro (Colocasia esculenta) have starches with high glycemic index [5]. But stored during several months, precooked taro flour induced high resistant starch contents [6]. In the context of treatment of non-insulindependent diabetes, breeding for precooked taro flour is of particular interest, as it will be easily incorporated into the dietaryprevention strategy. The objective of this study is the evaluation of the potential health benefits in controlling type 2 diabetes of resistant starches in taro (Colocasia esculenta) flour stored during 5 months in different storage conditions [7].

\section{Materials and Methods}

The fresh tubers of Colocasia esculenta were cooked, peeled, sliced and dried in a solar oven. Dried scallops were ground by sifting a hammer mill [8]. The flour obtained was stored in a polyethylene bag at $4{ }^{\circ} \mathrm{C}$ a until use Figure 1 .

\section{Result and Discussions}

The results are tabulated in the above Table 1 and are also shown in the above Figures $2-4$. The changes in blue index value and soluble sugars of cooked taro were also analysed. The results showed that irrespective of the particle size, the resistant starch significantly increased while BVI and soluble sugar significantly decreased. Significant correlations $(R=0.59, p<0.05 ; R=0.68$, $\mathrm{p}<0.05$ ), was observed between the resistant starch and the BVI and soluble sugar respectively. In fact, the degree of variations of each parameter depended mainly on the storage level. 


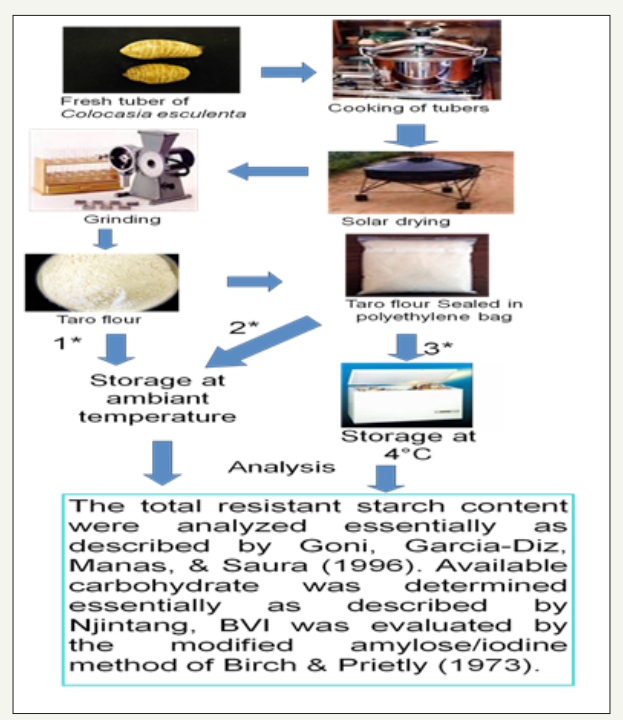

Figure 1:

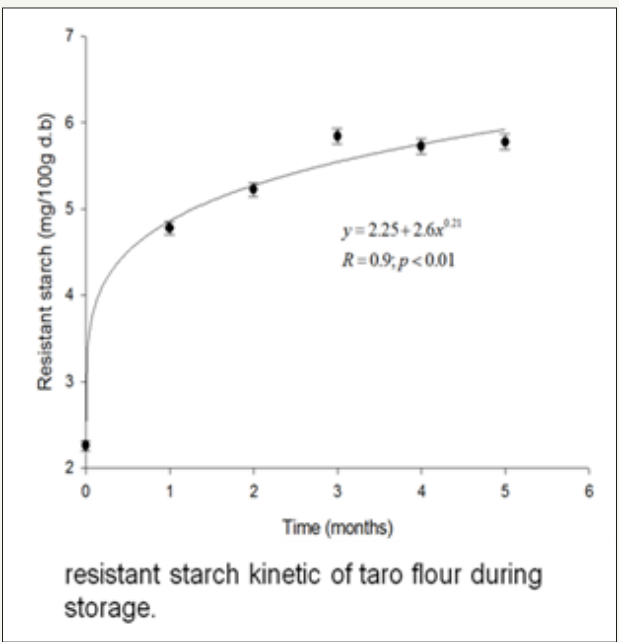

Figure 2: *storage in open polyethylene bag at ambient temperature (SOBAT).

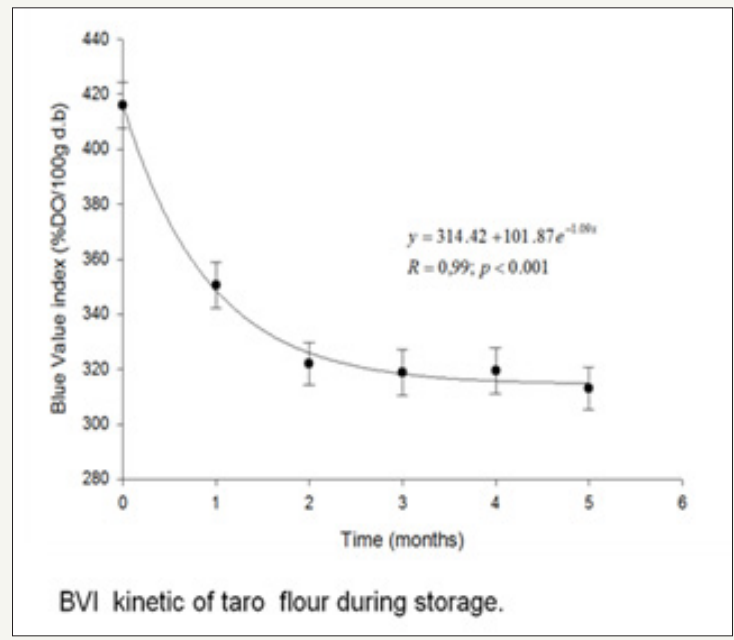

Figure 3: *storage in sealed polyethylene bag at ambient temperature (SSBAT). 


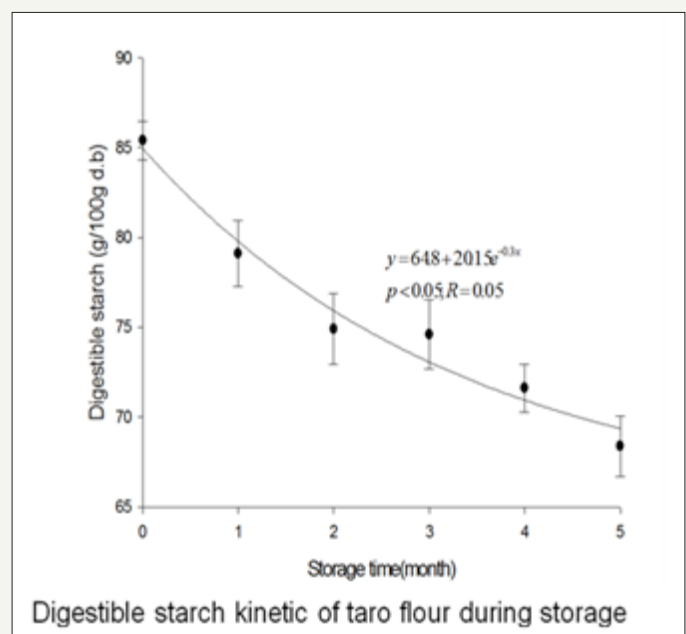

Figure 4:*storage in a sealed polyethylene bag in a refrigerator at $4{ }^{\circ} \mathrm{C}(\mathrm{SSBRT})$.

Table 1: Kinetic constants of water uptake of taro flours of different particle sizes stored under different conditions.

\begin{tabular}{|c|c|c|c|c|}
\hline Storage & Size $(\mu \mathrm{m})$ & Constants $\mathrm{k}\left(\mathrm{month}^{-1}\right)$ & $\mathrm{t} 1 / 2(\mathrm{month})$ & $\mathrm{R}^{2}$ \\
\hline \multirow{3}{*}{ SOBAT } & 75 & $0.29 \pm 0.07^{\mathrm{c}}$ & 2.41 & 0.84 \\
\cline { 2 - 5 } & 150 & $0.21 \pm 0.03^{\mathrm{b}}$ & 3.3 & 0.96 \\
\cline { 2 - 5 } & 250 & $0.18 \pm 0.01^{\mathrm{a}}$ & 3.87 & 0.98 \\
\cline { 2 - 5 } SSBAT & 75 & $0.46 \pm 0.01^{\mathrm{c}}$ & 1.5 & 0.86 \\
\cline { 2 - 5 } & 150 & $0.33 \pm 0.01^{\mathrm{b}}$ & 2.08 & 0.84 \\
\hline \multirow{3}{*}{ SSBRT } & 250 & $0.3 \pm 0.07^{\mathrm{a}}$ & 2.34 & 0.77 \\
\cline { 2 - 5 } & 75 & $0.82 \pm 0.02^{\mathrm{c}}$ & 0.8 & 0.99 \\
\cline { 2 - 5 } & 150 & $0.67 \pm 0.01^{\mathrm{b}}$ & 1.04 & 0.97 \\
\end{tabular}

\section{Conclusion}

Precooked taro flour will play an important role in the dietary management of metabolic disorders such as diabetes.

\section{References}

1. Perez E, Schultz FS, De Delahaye EP (2005) Characterization of some properties of starches isolated from Xanthosoma sagittifolium (tannia). Carbohydrate polymers 60(2): 139-145.

2. Buttriss JL, Stokes CS (2008) Dietary fiber and health: an overview. Nutrition Bulletin 33 (3): 186-200.

3. Liu Q (2005) Understanding starches and their role in food. In: Cui S (Ed.), Food carbohydrates: chemistry, physical properties, and applications. CRC Press/Taylor \& Francis Group, New York, USA, pp. 309-349.
4. Bruno CH, Colvin JT, Mullarney M P, Zinchuk AV (2003) The relative densities of pharmaceutical powders, blends, dry granulations, and immediate-release tablets. Journal of pharmaceutical technology pp. 64-80.

5. Azhar A, Farukh K (2013) Extraction of starch from taro (colocasia esculenta) and evaluating it and further using taro starch as disintegrating agent in tablet formulation with over all evaluation, Inventi Rapid: Novel Excipients, volume 2 .

6. Keren S, Bianco Peled H, Eyal S (2003) Polymorphism of resistant starch type III. Carbohydrate Polymers 54(3): 363-369.

7. Brich GG, Prietly RJ (1973) Degree of gelatinization of cooked rice. Starch 25: 98-100.

8. Goni I, Garcia Diz L, Manas E, Saura Calixto F (1996) Analysis of resistant starch: a method for foods and food products. Food Chemistry 56(4): 445-449.

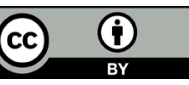

Creative Commons Attribution 4.0 International License

For possible submissions Click Here
Submit Article

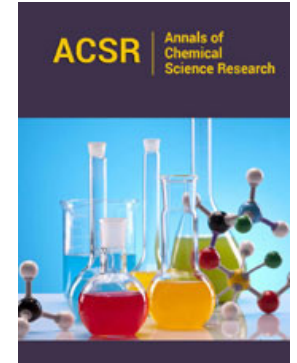

\section{Annals of Chemical Science Research}

\section{Benefits of Publishing with us}

- High-level peer review and editorial services

- Freely accessible online immediately upon publication

- Authors retain the copyright to their work

- Licensing it under a Creative Commons license

- Visibility through different online platforms 